\title{
Journal of Health Education and Health Promotion
}

\author{
www.journal.ihepsa.ir \\ Original Article
}

\section{Investigation of the Validity and Reliability of Attitude Towards Inter-Professional Education (IPE) in Health Care}

\section{Zohreh Sohrabi $^{1}$, Arezoo Saeed $^{1}, \underline{\text { Leili Salehi }}^{2 *}$}

1. Dept of Medical Education, Iran University of Medical Sciences, Tehran, Iran

2. Center for Health, Safety and Environment (HSE), Dept. of Health Education and Health Promotion, Alborz Ubiversity of Medical Sciences, Karaj, Iran

Article Information

\section{Article History:}

Received: 2016/02/22

Accepted: 2017/09/10

Available online: 2018/01/30

\section{IJHEHP 2018; 6(1):012-019}

\section{DOI:}

10.30699/acadpub.ijhehp.6.1.12

\section{Corresponding Author:}

\section{Dr.Leili Salehi}

Center for Health, Safety and Environment (HSE), Dept. of Health Education and Health Promotion, Alborz Ubiversity of Medical Sciences, Karaj, Iran

Tel: 026-34336008

Email:

leilisalehi83@yahoo.com

Use your device to scan and read the article online

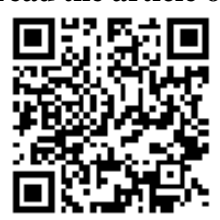

\section{Abstract}

Background and Objective: Despite the acceptance of Inter-professional education (IPE) as an approach to improve the participation process among members of the health department, few studies have used valid and reliable tools to evaluate the attitude. This study aimed to provide a valid and reliable tool for investigating the attitude towards interprofessional education in health care.

Methods: This study was conducted to evaluate the attitude towards IPE of 90 faculty members of Iran and Tehran University of Medical Sciences in 2015. Initial instrument- compromised 15 items, Likert type- was adopted from previous studies. Impact item score, content validity and content validity index were assessed by 10 participants and 10 experts respectively; construct validity was evaluated by using exploratory factor analysis. Reliability of the scale was evaluated by internal consistency calculation and with the test-retest.

Results: According to the impact item score of above 1.5, the index of content validity of 0.62 and the content validity index of $0.7,12$ questions were preserved. Based on exploratory factor analysis, 12 items were kept in scale. Considering an eigenvalue above 1 , two factors were extracted. This instrument was able to predict $52 \%$ of the change that occurred in the total scale.

Conclusion: The results of this study indicated the strength of the factor structure and reliability of an instrument for measuring students' attitudes towards IPE scale in health care. The results of study can assess attitude towards IPE in universities and other educational institutes.

KeyWords: Validity, Reliability, Psychometric, Attitude, Inter-Professional Education.

Copyright (C) 2017 Iranian Journal of Health Education and Health Promotion. All rights reserved.

How to cite this article:

Sohrabi Z, Saeed A, Salehi L. Investigation of the Validity and Reliability of Attitude Towards InterProfessional Education (IPE) in Health Care. Iran J Health Educ Health Promot. 2018; 6 (1) : 12-19

Sohrabi, Z., Saeed, A., Salehi, L.(2018). Investigation of the Validity and Reliability of Attitude Towards Inter-Professional Education (IPE) in Health Care. Iranian Journal of Health Education and Health Promotion, 6 (1) : 12-19 
بروسى روايى و پايايى ابزار نترش به آموزش بين حرفهاى (IPE)

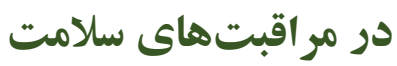

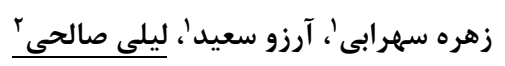

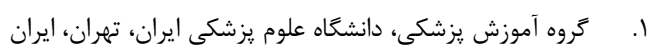

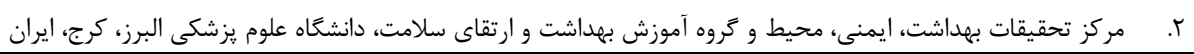

\begin{tabular}{|c|c|}
\hline جكيله & 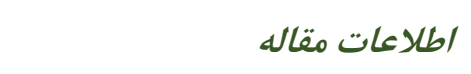 \\
\hline زمينه و هدف: علىرغم يذيرش آموزش بين حرفهاى بهعنوان رويكردى براى بهبود روند مشاركت & تاريخجة مقاله \\
\hline بين اعضاى كروه سلامت، مطالعات اندكى از ابزارهاى روا و بايا براى ارزيابى نَكرش به آن استفاده كرده & 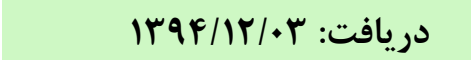 \\
\hline اند. اين مطالعه با هدف تهيئ ابزارى رواو وِايا براى ارزيابى نكرش به آموزش بين حرفهاى انجام شد. & 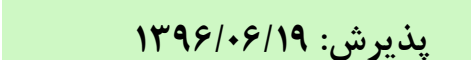 \\
\hline مواد و روشها: اين مطالعه به منظور روانسنجى مقياس نكرش به آموزش بين حرفهاى روى ج & انتشا, آنلاس: ••|/|| \\
\hline 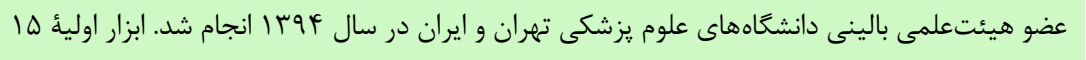 & \\
\hline سؤالى با مقياس ليكرت از مطالعات قبلى اقتباس شده بود كه پس از كسب اجازه به زبان فارسى ترجمه & IJHEHP 2018; 6(1):012-019 \\
\hline شد. ضريب تأثير، شاخص روايى و نسبت روايى محتوا به ترتيب با قضاوت • ا نفر از اعضاى مطالعه و & نويسندهُ مسئول: \\
\hline 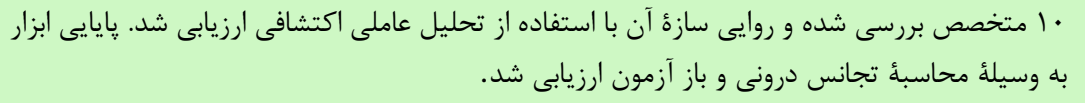 & د دكتر ليلى صالحى \\
\hline يافته ها: براساس شاخص ضريب تأثير بالاى ه/1 و شاخص روايى محتواى بالاى بو/• و نسبت روايى & كروه آموزش و ارتقاى سلامت، دانشكاه \\
\hline 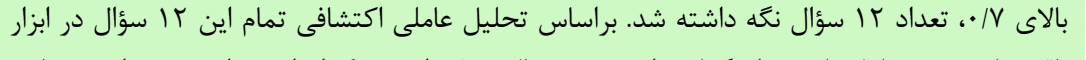 & علوم يزشكى البرز، كرج، ايران \\
\hline 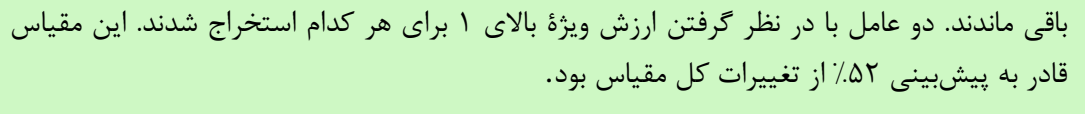 & 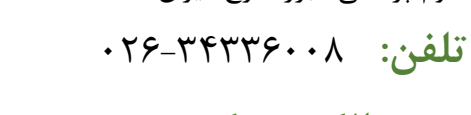 \\
\hline نتيجدهَيرى: نتايج اين مطالعه شاهد مناسبى دربارة استحكام ساختار عاملى و پايايى ابزار نكَرش به & 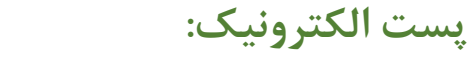 \\
\hline آموزش بين حرفهاى در مراقبتهاى سلامتى است. اين نتايج مىتواند براى سنجش ميزان نكَرش به & leilisalehi83@yahoo.com \\
\hline آموزش بين حرفهاى در مراقبتهاى سلامتى در دانشكاهها و ساير مؤسسات آموزشى استفاده شود. & براى دانلود اين مقاله، كد \\
\hline كلمات كليدى: روايى، يايايى، روانسنجى، نكرش، آموزش بين حرفهاى. & 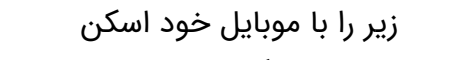 \\
\hline كبيدايت O: حق حاب، نشر و استفاده علمى اذ اين مقاله براى مجلة آموزش بهاشت و ارتقاى سلامت محفوظ است. & كنيد \\
\hline
\end{tabular}

مقإ

آموزش بين حرفهاى سبب ييشبرد عملكرد مشاركتى

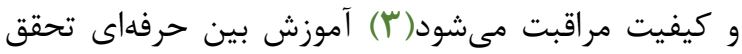
اهداف كلى ارائٔ درمان ايمن، مطلوب و مبتنى بر جامعه را در

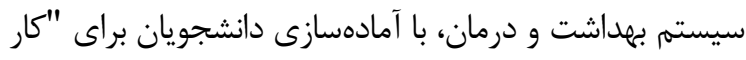

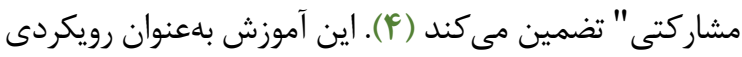
نوين و كارآمد در ارتقاى كيفيت خدمات و متناسب با تغييرات

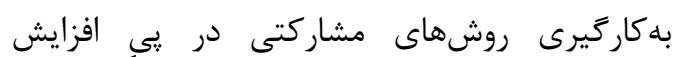
بيجيدگى هاى نظام مراقبتهاى سلامتى و محدوديت منابع با توجه به وضعيت مددجويان اجتنابنايذير است (1).

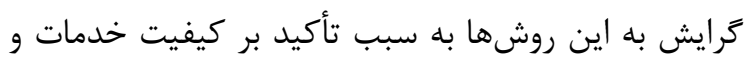
كارايى آن افزايشيافته است (؟). 
محتوايى و صورى يرسشنامه به ترتيب با استفاده از نظرهاى

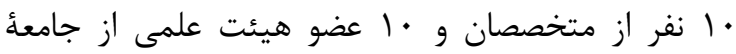

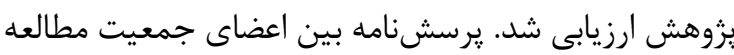

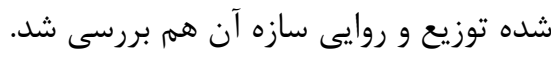

در بخش كمّى مطالعه، بهمنظور تعيين روايى از روايى ) رديى

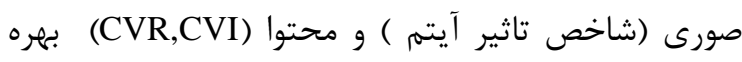

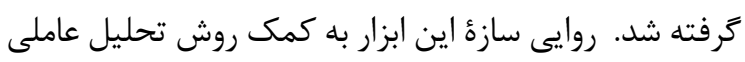
اكتشافى ارزيابى شد.

تحليل عاملى اكتشافى با استفاده از آزمون كيسرــ ماير

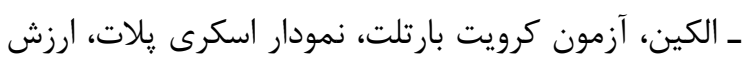

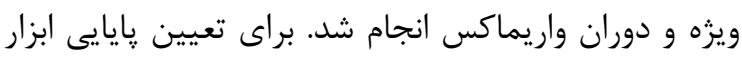

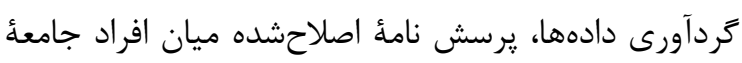

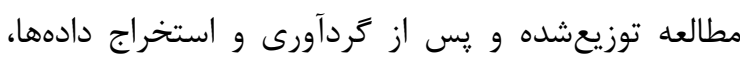

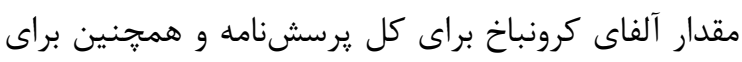

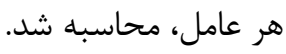

يافتهها

ميانخين سنى اعضاى هيئتعلمى بررسى شده FV/qV $\pm V / \mid F$ مشخصهاى جمعيت شناختى مشاركت كنندكان در جدول

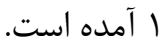

\section{نتايج سنجش روايى صورى:}

الف. كيفى: ينج كويه اصلاح شدند.

ب. كمى: گويأه دو، حذف و بقيئ كويهها حفظ شدند.

\section{نتايج سنجش روايى محتوايى}

با تعيين نسبت روايى و شاخص روايى محتوا صورت كرفت.

الف: نتايج سنجش نسبت روايى محتوا (CVR)

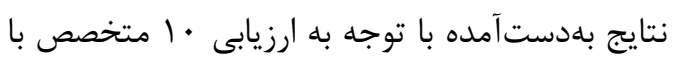

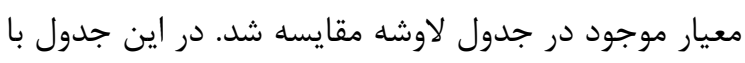

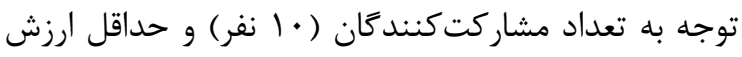

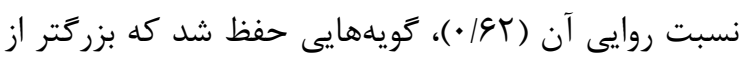

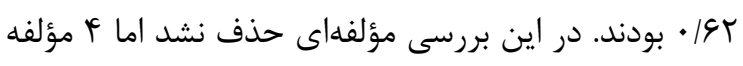

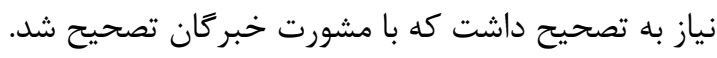

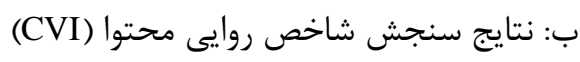

جهانى توجه همكان را به خود جلب كرده است (ه). با ارائٔ

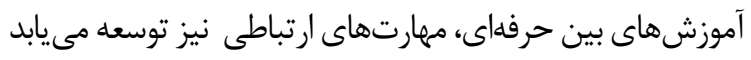

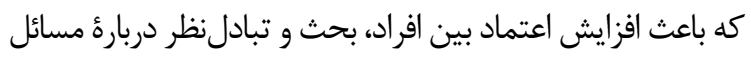
بيماران، روشن شدن نقشهاى افراد و افزايش احتمال ارائٔ بيشتر و بجتر مراقبت به بيمار مىشود (1- (9). در راستاى ارتقاى رويكر دهاى مشاركتى در مراقبتهاى

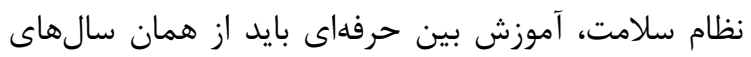

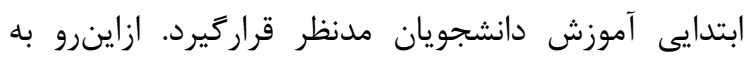

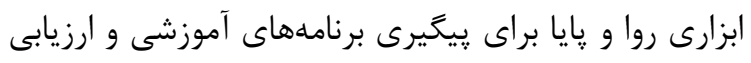

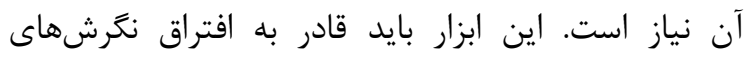
كروههاى متفاوت جمعيتى باشد (9).

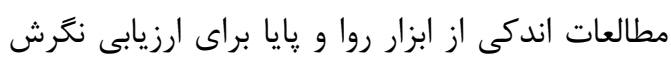
افراد به آموزش بين حرفهاى استفاده كردهاند.

در همين راستا مىتوان از مقياس معتبر 1/ سؤالى

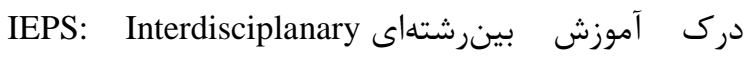
Education Perception Scale

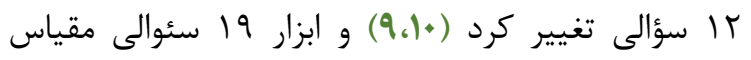

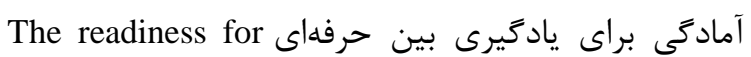
نات (interprofessional learning scale) :RIPLS ثبات و تجانس درونى آن ارزيابى شده است (1) (1). اغلب از

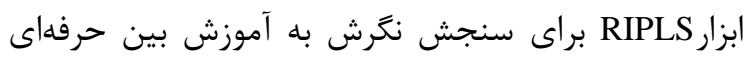

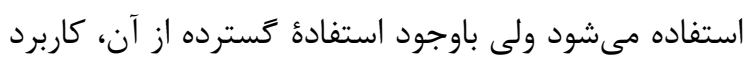
آن در شكل كامل صحيح نيست (9). با توجه به اهميت آموزش بين حرفهاى (Iا) و وجود نداشتن

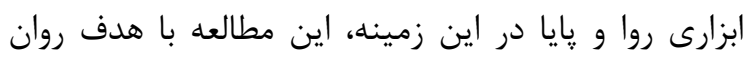

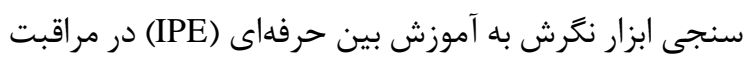
هاى سلامت انجام شد.

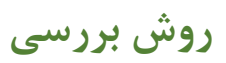

اين مطالعهُ روانسنجى با هدف اعتبار سنجى مقياس رورس

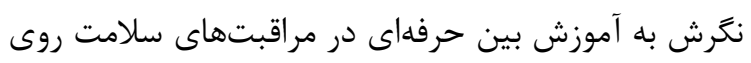

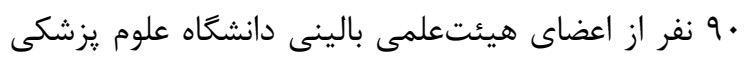

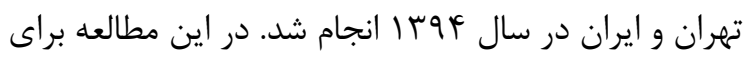

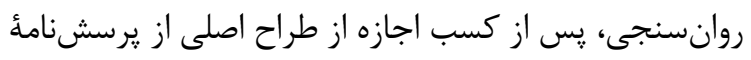

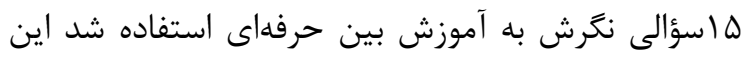

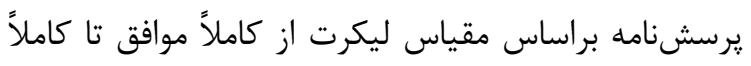

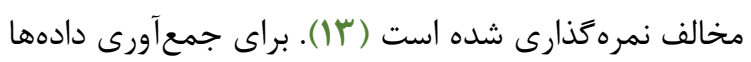

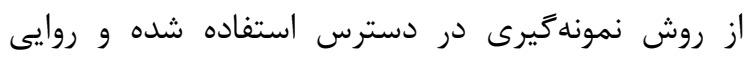


در اين بررسى سؤالهاى بالاى V9/ • حفظ و سؤال

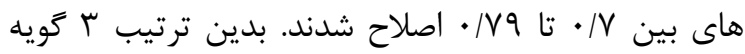
حذف شد و ه كويه نياز به اصلاح داشتند.

جدول ا. مشخصههاى جمعيت شناختى استادان مطالعه

\begin{tabular}{|c|c|c|c|c|}
\hline \multicolumn{2}{|c|}{ ويزَّى هاى جمعيتشناختى } & \multicolumn{2}{|c|}{ 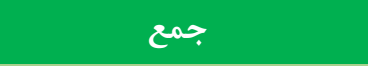 } & \multirow{2}{*}{ تعداد (درصد) } \\
\hline$r \cdot-r q$ & \multirow{5}{*}{ سن (سال) } & \multirow{5}{*}{$q \cdot(1 \cdots)$} & . & \\
\hline$r \cdot-r q$ & & & Ir & $(\mid F / \mathcal{F})$ \\
\hline$f \cdot-r q$ & & & (i) & $(\varphi \Delta / \varphi)$ \\
\hline$\Delta \cdot-\Delta q$ & & & $r \cdot$ & ( \\
\hline 9 ال عال به بالا & & & 4 & $(g / V)$ \\
\hline مرد & \multirow{2}{*}{ 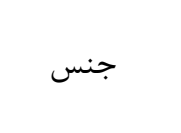 } & $q \cdot(1 \cdots)$ & iq & $(\Delta) / 1)$ \\
\hline زن & & & Fe & $(F \wedge / q)$ \\
\hline 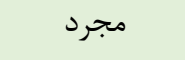 & \multirow{2}{*}{ وضعيت تأهل } & $q \cdot(1 \cdots)$ & 9 & $(1 \cdot)$ \\
\hline متأهل & & & $\wedge 1$ & $(9 \cdot)$ \\
\hline استاديار & \multirow{3}{*}{ مرتبأه علمى } & $q \cdot(1 \cdots)$ & $\Delta \cdot$ & $(\Delta \Delta / \varnothing)$ \\
\hline 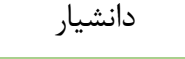 & & & זr & $(r \varepsilon / V)$ \\
\hline استاد & & & v & $(\mathrm{V} / \Lambda)$ \\
\hline 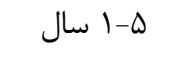 & \multirow{6}{*}{ سوابق تدريس } & $q \cdot(1 \cdots)$ & rl & $(\Gamma / / \Gamma)$ \\
\hline 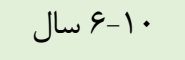 & & & 10 & $(19 / V)$ \\
\hline ل 11-11 سال & & & $r \cdot$ & $(T / / T)$ \\
\hline 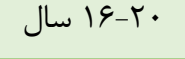 & & & IV & $(1 / / 9)$ \\
\hline 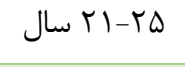 & & & ir & $(\mid r / \Gamma)$ \\
\hline عץ سال به بالا & & & $\Delta$ & $(\Delta / 9)$ \\
\hline
\end{tabular}

قراركرفته و واريانس نكرش به آموزش بين حرفهاى اعضاى هيئتعلمى را تبيين مى كنند.

در اين مطالعه از هر دو جرخش واريماكس و ابليمين

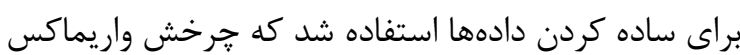
با ابزار اصلى منطبق بود و بر اين اساس ك حيطه استخراج

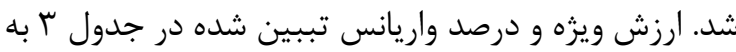
نمايش كذاشته شده است.

براساس ماتريس همبستگى جرخش يافته ميان

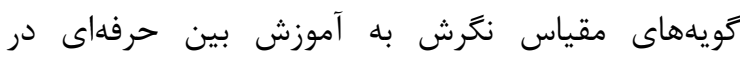

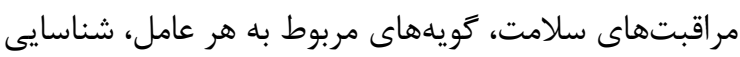
شده و هر عامل نامگذارى شد و اين نامگذارى به كمك هرئ

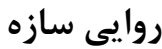

ابتدا براى بررسى روايى سازه، آزمون كفايت

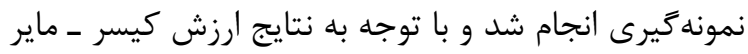

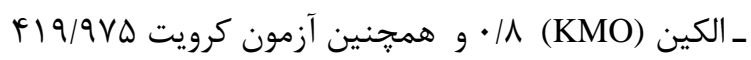
در سطح معنى دارى I •.|•> حداقل شرايط براى انجام تحليل عاملى اكتشافى برقرار بود. در اين يزوهش براى استخراج عوامل از شيوء تجزيه و

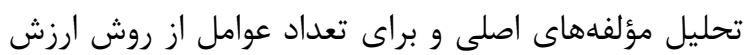

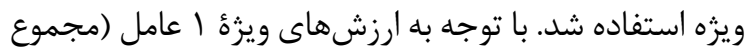

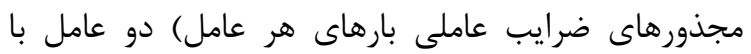

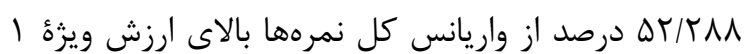


متخصصان و با توجه به نامخذارى اوليئ مقياس به دستِ آموزش بين حرفهاى (تعامل محور)"و "آموزش بين سازندكان آن، انجام شد. به اين ترتيب دو عامل استخراجى رفهاى (انطباق حرفهاى)" نامخذارى شدند.

جدول r. ضريب تأثير و شاخص روايى محتواى تويهها

\begin{tabular}{|c|c|c|c|c|c|}
\hline \multicolumn{3}{|c|}{ I VC } & \multirow{2}{*}{ RVC } & \multirow{2}{*}{ ضريب } & \multirow{2}{*}{ كويهها } \\
\hline وضوح & سادَى & ارتباط & & & \\
\hline$\cdot / 9$ & $\cdot 11$ & .19 & $\cdot \mid \Lambda$ & r/qr & 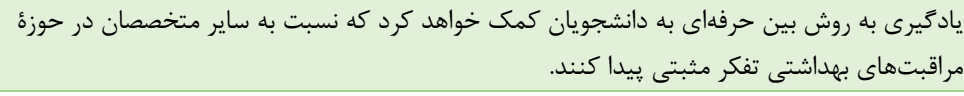 \\
\hline$\cdot / r$ & $\cdot \pi$ & .19 & $\cdot \pi$ & .194 & 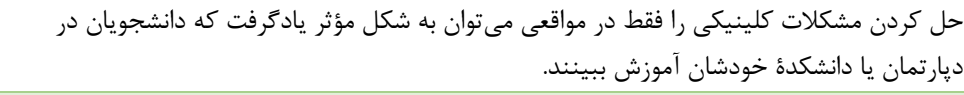 \\
\hline$\cdot / \Lambda$ & $\cdot / V$ & 1 & 1 & $r / r$ & 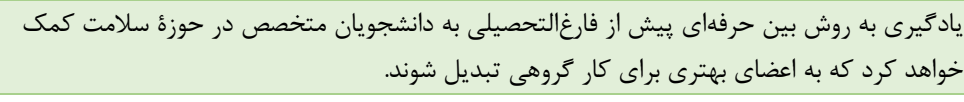 \\
\hline$\cdot / V$ & $\cdot 1 /$ & 1 & 1 & $r / r V$ & 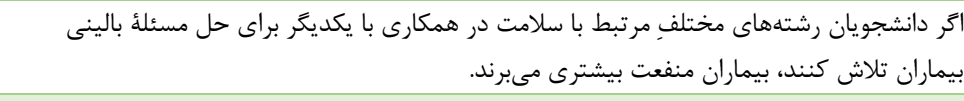 \\
\hline$\cdot 10$ & $\cdot 10$ & $\cdot / 1$ & . & 1/99 & 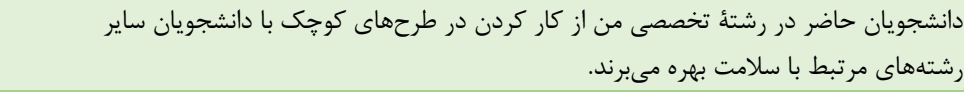 \\
\hline$\cdot 19$ & .19 & 1 & $\cdot / 1$ & $r / 9 F$ & فراكرفته شود. \\
\hline$\cdot 10$ & $\cdot / V$ &.$/ 9$ & $\cdot 1 /$ & $r / \cdot v$ & دانشجويان كمى به روش بين حرفهاى بهصورت آشكارى در تشخيص ماهيت و نوع مشكلات بيماران به \\
\hline$\cdot / r$ & $\cdot \pi$ & .19 & $\cdot$ & I/Ar & يادَيرى گروهى براى دانشجويان مقطع كارشناسي رشتهٔ مراقبتهاى بهداشتى ضرورى نيست. \\
\hline$\cdot / \Lambda$ & $\cdot 19$ & $\cdot / \mathrm{A}$ & $\cdot / \Lambda$ & r/qu & 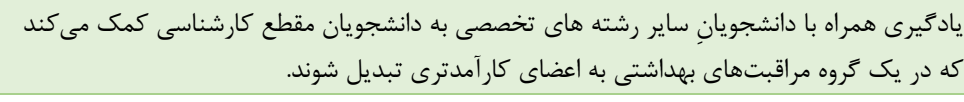 \\
\hline$\cdot / \Lambda$ & $\cdot / V$ & 1 & $\cdot / \Lambda$ & $r / r V$ & يادَّيرى به روش بين حرفهاى، توانايى دانشجويان را براى درك مشكلات كلينيكى افزايش خواهد داد. \\
\hline$\cdot / \Lambda$ & $\cdot 1 \Lambda$ & 1 & $\cdot / \Lambda$ & $4 / 14$ & يادكيرى بهروش بين حرفهاى به دانشجويان كمك خواهد كرد كه محدوديتهاى تخصصى خود را \\
\hline$\cdot / \Lambda$ & $\cdot / V$ & $\cdot / \mathrm{V}$ & $\cdot 19$ & $r / 94$ & و بر هم احترام بكذارند. \\
\hline$\cdot / 9$ & $\cdot / \mathrm{V}$ & $\cdot 19$ & $\cdot / 4$ & $r / r v$ & يادكيرى به روش بين حرفهاى به دانشجويان كمك خواهد كرد كه بهتر با بيماران و ساير متخصصان \\
\hline$\cdot 19$ & $\cdot / \Lambda$ & 1 & 1 & $r / r$ & يادَيرى مهارتهاى كارِ كروهى براى تمام دانشجويانِ رشتهُ مراقبتهاى بهداشتى ضرورى است. \\
\hline$\cdot / \mathrm{V}$ & .19 &.$/ 9$ & .19 & $r / r$ & مَّخشد. موزش حرفهاى به دانشجويان در دوران تحصيل، روابط كارى آنها را ٍِ از فاغ التحصيلى بهبود \\
\hline
\end{tabular}

جدول شماره س. ارزش ويثه و درصد واريانس تبيين شده

\begin{tabular}{|c|c|c|c|c|c|c|c|c|c|}
\hline \multirow[t]{2}{*}{ مؤلفه ل } & \multicolumn{3}{|c|}{ مقادير خرخش يافته } & \multicolumn{3}{|c|}{ مقادير جرخش نيافته } & \multicolumn{3}{|c|}{ مقادير ويزه } \\
\hline & درصد تجمعى & درصد واريانس & مجموع & درصد تجمعى & درصد واريانس & مجموع & درصد تجمعى & درصد واريانس & مجموع \\
\hline 1 & $\Delta / \cdot 1 T$ & $F \mid / \& V V$ & FI/VGG & $\Delta / \cdot 1 T$ & $F I / G V V$ & FI/VGG & 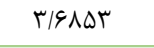 & $r \cdot / \cdot v 1$ & $r \cdot / v i$. \\
\hline r & 1/Ta & $1 \cdot / T \Delta T$ & $\Delta T / T \Lambda \Lambda$ & I/TEK & $1 \cdot / \pi \wedge \Lambda$ & $\Delta T / T \Lambda \Lambda$ & $r / \Delta \wedge 9$ & rI/QVA & $\Delta T / T \wedge \Lambda$ \\
\hline r & $\cdot / 919$ & $N / T / Q$ & $4 \cdot 10 \cdot r$ & & & & & & \\
\hline f & .19 .4 & V/DQT & $G N / \Delta F$ & & & & & & \\
\hline$\Delta$ & $\cdot / \Lambda 9 \Delta$ & $V(r)$. & $V D / R G F$ & & & & & & \\
\hline 4 &. & $\Delta / 9 \wedge \vee$ & $\Lambda \cdot / 9 \Delta \mathrm{T}$ & & & & & & \\
\hline v & $\cdot / \Delta \Delta \cdot$ & $f / f \Delta \Lambda$ & $\Lambda \Delta / \Delta T r$ & & & & & & \\
\hline$\wedge$ & $\cdot / \Delta \Delta$. & $f / r \ldots$ & А৭/ArV & & & & & & \\
\hline 9 & . kFtr & r/qIV & $q T / F \Delta F$ & & & & & & \\
\hline
\end{tabular}




\begin{tabular}{|c|c|c|c|}
\hline 1. &.$/ K F V$ & r/А१| & $q \& / T F \mid$ \\
\hline 11 & . & $1 / 999$ & $q / / T 4$. \\
\hline IT &.$/ 199$ & $1 / 99$. & $1 \ldots /$. \\
\hline
\end{tabular}

جدول شماره ؟. عوامل استخر اجشدة نهايى محتواى سؤالهاى مربوط به هر عامل و نامَذارى آن

\begin{tabular}{|c|c|c|}
\hline شمارؤ َّويههاى مربوط به هر عامل & 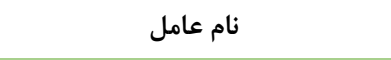 & 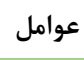 \\
\hline r. & آموزش بين حرفهاى (تعامل محور) & 1 \\
\hline • • י V، ه، זr & آموزش بين حرفهاى (انطباق حرفهاى) & r \\
\hline
\end{tabular}

درصد از واريانس ابزار آموزش بين حرفهاى آنان را تبيين مى

كرد (1) (1).

نتايج مطالعأ حاضر نشان داد كه ميزان ضريب همسانى

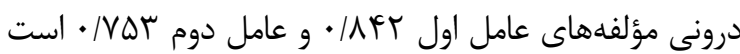

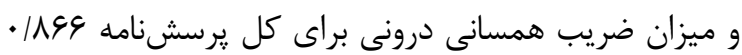

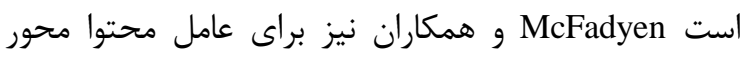

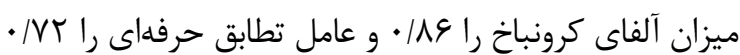

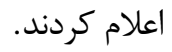

بررسى همسانى درونى سؤالات يرسشنامه نشان داد

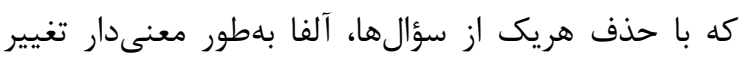

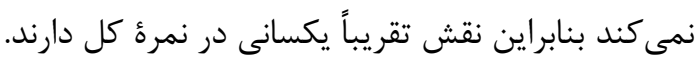
بايد كفت كه اين باور در ايران وجود دارد كه نكرش افراد

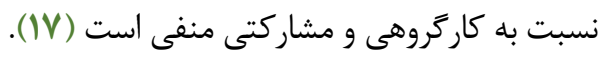
Lindquist ارزيابى نكرش اعضاى كروه سلامت نسبت به مهارت بين

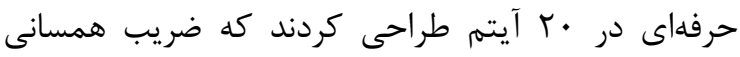

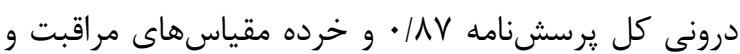

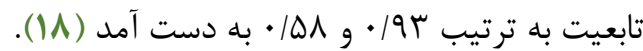
در مطالعة كنونى ضرايب همبستكى بين نمرههاى 10

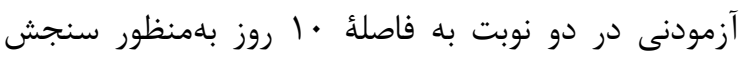

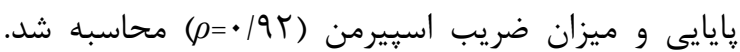

$$
(P<\cdot / \cdot \Delta)
$$

براساس يافتههاى مطالعُ حاضر عامل اول (آموزش

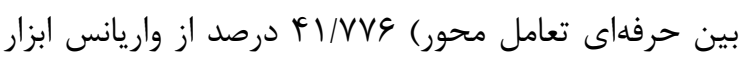
نكَرش به آموزش بين حرفهاى را تبيين مى كرد كه بيانكر اهميت تعاملها در آموزش بين حرفهاى است.
در اين يزروهش بهمنظور تعيين يايايى مقياس نكرش

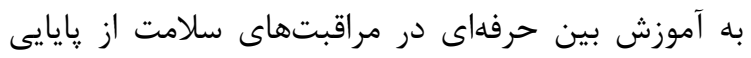

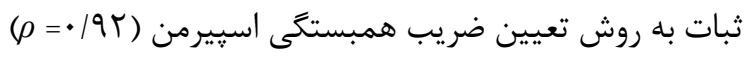

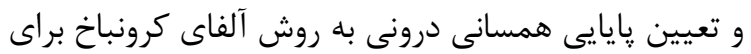
كل :برسشنامه (1) • • =

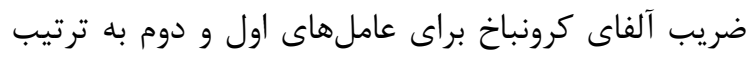

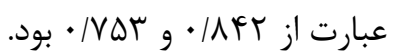

\section{بحث}

اين مطالعه با توجه به نبودِ ابزارى رواو وِايايى درباره

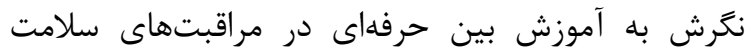
(IPE: Interprofessional Education) براى تشخيص كفايت نمونهَيرى از آزمون كيسر ماير

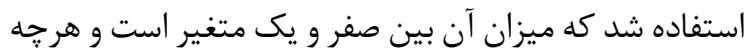
ميزان آن بالاتر باشد تحليل عاملى بهتر خواهد بود و و حداقل

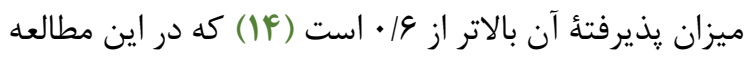

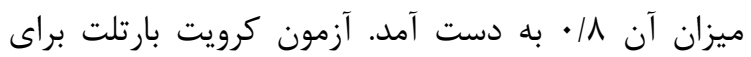

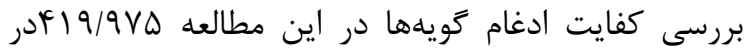

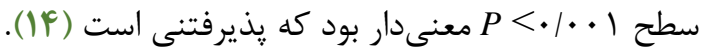
در اين مطالعه براساس קرخش واريماكس دو عامل استخراج شد كه اين دو عامل براساس مطالعهُ اصلى و ورانل

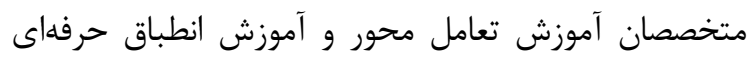

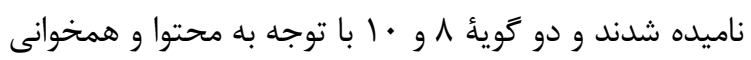
موضوعى با همديخر جابجا شدند. همسو با نتايج مطالعه حاضر، Sargeant و همكاران در تلاش براى طراحى و ارزيابى ابزارى بهمنظور بررسى

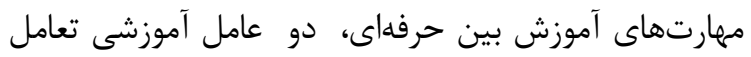
محور و محتوا محور را استخراج كردند كه اين دو عامل و 


$$
\begin{aligned}
& \text { يا موسسؤ آموزشى استفاده كرد و همخوانى تعداد عوامل آن } \\
& \text { با ابزار اصلى را مىتوان ناشى از نقش اصلى و كليدى اين }
\end{aligned}
$$

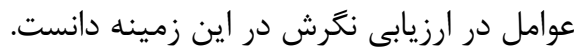

$$
\begin{aligned}
& \text { مشغلهُ كارى و فرصت كافى نداشتنِ اعضاى هيئت علمى } \\
& \text { براى ير كردن ثرسشنامه از محدوديتهاى اين مطالعه است }
\end{aligned}
$$

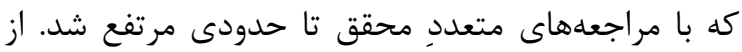

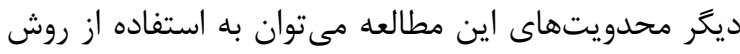

$$
\begin{aligned}
& \text { نمونهَيرى در دسترس براى انتخاب نمونه اشاره كرد. }
\end{aligned}
$$

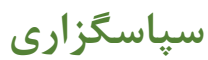

$$
\begin{aligned}
& \text { اين يزوهش، حاصل بخشى از پاياننامؤ كارشناسى }
\end{aligned}
$$

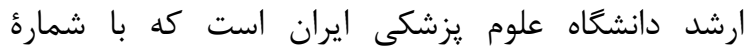

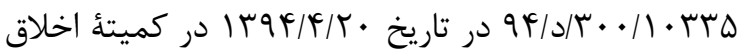

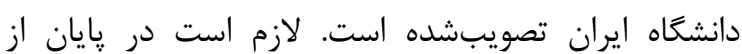

$$
\begin{aligned}
& \text { همكارى تمام كسانى كه در اين مطالعه شركت داشتهاند، }
\end{aligned}
$$

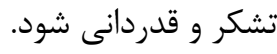

$$
\begin{aligned}
& \text { تعارض در منافع } \\
& \text { هيجَّونه تعارض منافعى بين نويسندكان كزارش } \\
& \text { نشده است. } \\
& \text { نتبجه تيرى }
\end{aligned}
$$

\section{References}

1. Irajpour AR, Alavi M, Abdoli S, Saberizafarghandi MB. Challenges of interprofessional collaboration in Iranian mental health services: A qualitative investigation. Iran J Nurs Midwifery Res. 2011; 17(2):1-9.

2. Fichtner CG, Hardy D, Patel M, Stout CE, Simpatico TA, Dove H, et al. A self-assessment program for multidisciplinary mental health teams. Psychiatr Serv. 2001; 52(10):1352-7

https://doi.org/10.1176/appi.ps.52.10.1352 PMid:11585952

3. Reeves S. Why we need interprofessional education to improve the delivery of safe and effective care. Interface - Comunicação, Saúde, Educação. 2016;20:185-9. https://doi.org/10.1590/180757622014.0092

4. Amini SB, Keshmiri F, Soltani Arabshahi K, Shirazi M. Development and validation of the interprofessional collaborator communication skill core competencies. RJMS. 2014;20(115):8-16.

5. Reeves S, Zwarenstein M, Goldman J, Barr H, Freeth D, Koppel I, et al. The effectiveness of interprofessional education: key findings from a new systematic review. J Interprof Care. 2010; 24(3):2304. https://doi.org/10.3109/13561820903163405 PMid:20178425
6. Zeyghami Mohammadi S, Haghighi S. The association between nurses' communication skills and nurse-physician relationship and collaboration in Alborz hospital of Karaj in 2008. Medical Science Journal of Islamic Azad Univesity-Tehran Medical Branch. 2009;19 (2):121-7.

7. Hudson B. Pessimism and optimism in interprofessional working: the Sedgefield integrated team. J Interprof Care. 2007;21(1):3-15 https://doi.org/10.1080/13561820600991850 PMid:173 65370

8. Pearson D, Pandya H. Shared learning in primary care: participants' views of the benefits of this approach. J Interprof Care. 2006; 20(3): 302-13 . https://doi.org/10.1080/1 $3561820 \quad 60064967$ PMid:16777797

9. Lie DA, Fung CC, Trial J, Lohenry K. A comparison of two scales for assessing health professional students' attitude toward interprofessional learning. Medical education online. 2013;18(1):21885. https://doi.org/10.3402/meo.v18i0.21885 PMC3849511

10. Luecht RM, Madsen MK, Taugher MP, Petterson BJ. Assessing professional perceptions: Design and validation of an interdisciplinary education perception 
scale. J Allied Health. 1990;19(2):181-91. PMid: 2365636

11. Parsell G, Bligh J. The development of a questionnaire to assess the readiness of health care students for interprofessional learning (RIPLS). Medical education. 1999;33(2):95-100 https:// doi.org/10.1046/j.1365-2923.1999 .00298.x PMid:10211258

12. Thannhauser J, Russell-Mayhew S, Scott C. Measures of interprofessional education and collaboration. J Interprof Care. 2010;24(4):336-49 https://doi.org /10.3109/13561820903442903 PMid:20540613

13. Curran VR, Sharpe D, Forristall J. Attitudes of health sciences faculty members towards interprofessional teamwork and education. Medical education. 2007;41(9):892-6 https://do i.org/10.1111/j.13652923.2007.02823.x PMid:17696982

14. Kaiser HF. An index of factorial Simplicity .Psychometrika1974;39(1):31-6 https://doi.org/10. $\underline{1007 / \mathrm{BF} 02291575}$

15. Sargeant J, Hill T, Breau L. Development and testing of a scale to assess interprofessional education (IPE) facilitation skills. J Contin Educ Health Prof 2010; 30(2):126-31. 9 .
16. Beigi M, Shirmohammadi M. Attitudes toward teamwork: are Iranian university students ready for the workplace?. Team Performance Management: An International Journal. 2012; 18 (5/6): 295-311. https://doi.org/10 .1108/13527591211251087

17. MacDonald MB, Bally JM, Ferguson LM, Murray BL, Fowler-Kerry SE, Anonson JM. Knowledge of the professional role of others: A key interprofessional competency. Nurse education in practice. 2010;10(4):238-42 https://doi.org/10.1016/ j.nepr. 2009.11.012 Pmid:203 08019

18. Lindqvist S, Duncan A, Shepstone L, Watts F, Pearce S. Development of the 'Attitudes to Health Professionals Questionnaire'(AHPQ): A measure to assess interprofessional attitudes. J Interprof Care. 2005;19(3):269-79 https://doi.org/10.1080/1356182 0400026071 PMid: 16029980

19. Braithwaite J, Westbrook M, Nugus P, Greenfield D, Travaglia J, Runciman W, et al. A four-year, systemswide intervention promoting interprofessional collaboration. BMC health services research. 2012;12

(1):99.https://doi.org/10.1186/1472-6963-12-99 PMC 3359212

20. Parsell G, Bligh J. Interprofessional learning. Postgraduate Medical Journal. 1998;74 (868): 89 -95. https://doi.org/10.1136/pgmj.74.868.89 PMC2360816

21. Cooke S, Chew- Graham C, Boggis C, Wakefield A. 'I never realised that doctors were into feelings too': changing student perceptions through interprofessional education. Learning in Health and Social Care. 2003;2(3):137-46. https://doi.org/ $\underline{10.1046 / j .14736861 .2003 .00050 . \mathrm{x}}$ 